\title{
Using vacuum conductive drying to improve the environmental friendliness of materials
}

\author{
Liliya Lyamina ${ }^{1}$, Ruslan Safin ${ }^{1}$, Shamil Mukhametzyanov ${ }^{1 *}$ and Olga Zybina ${ }^{2}$ \\ ${ }^{1}$ Kazan National Research Technological University, Kazan, Russia \\ ${ }^{2}$ National Technology Initiative Center for Advanced Manufacturing Technologies based on the \\ Institute of Advanced Manufacturing Technologies of Peter the Great St. Petersburg Polytechnic \\ University Polytechnicheskaya, 29, St.Petersburg, 195251, Russia
}

\begin{abstract}
To minimize the risk of rotting damage to wood materials, special antiseptic preparations with biocidal, fungicidal and insecticidal properties are widely used. Many of them contain highly volatile chemicals that are toxic to humans and harmful to the environment. The development of approaches to reduce the emission of harmful substances from wood materials is an important problem in improving the environmental friendliness of construction and finishing materials. The paper describes a method for increasing the biostability of chipboard based on polyvinyl alcohol binder by chemical-free high-temperature treatment (thermal modification). The paper presents the results of experimental studies of vacuum-conductive drying of wall panels made of thermally modified filler. Drying curves for wall panels were plotted depending on various parameters: temperature conditions, different chipboard thickness, and the residual pressure in the vacuum chamber. The work performed revealed that panels with a thermally modified filler dry much faster than those with untreated filler and without the release of chemical compounds harmful to humans and the environment.
\end{abstract}

\section{Introduction}

The development of eco-friendly chipboard materials has long been a hot topic. However, research is mainly aimed at reducing the toxicity of the adhesive component of this composite, and therefore solutions are proposed to reduce phenol emissions by introducing various additives or replacing phenol-containing resins with other more environmentally friendly binders [2-4].

Previously published research was aimed at developing the chipboard technology, where polyvinyl alcohol was used as a binder [1]. This technology can be used in the furniture board production. At the same time, it is reasonable to produce wood-chip panels for heat insulation and soundproofing. In this case, to prevent the growth of mold fungi and various wood-destroying microorganisms, a necessary condition is the biological protection of wood particles. For this purpose, modification with various chemical compositions is usually used [2-4]. However, chemical modification is dangerous both for humans and for

*Correspondingauthor:joker775.87@mail.ru 
the entire environment. In this regard, in recent years, research in the field of hightemperature treatment (thermal modification) of wood has come to the fore, which makes it possible to increase biostability without the use of chemicals [2].

So, creating eco-friendly wall materials should involve considering this type of pretreatment of wood filler and its impact on the technological process of production of chipboards based on a polyvinyl alcohol binder.

\section{Methods and Materials}

Initially, the temperature conditions for processing wood material (sawdust) were selected. The heat treatment temperature was $220^{\circ} \mathrm{C}$. Thermal modification was carried out in a dense bed in a container placed in a chamber furnace. The camera and the container are shown in Figure 1.

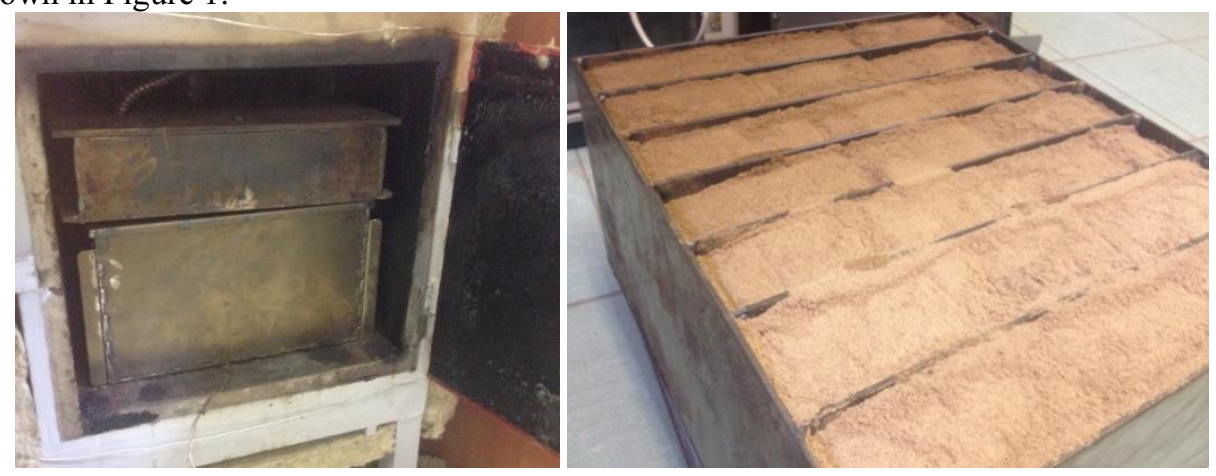

Fig. 1. Experimental unit for thermal modification of crushed wood in a dense bed.

2 to $5 \mathrm{~mm}$ sawdust were fed to special sections, which were loaded into the chamber furnace. After that, the furnace was hermetically closed, and the processing temperature was set to $220^{\circ} \mathrm{C}$. After the set temperature was reached inside the material layer, determined using a pre-installed thermocouple, the wood material was kept under these conditions for 3 hours. Then the unit was switched off, and the thermally modified wood material was self-cooled in the closed furnace until the temperature inside the layer fell below the self-ignition temperature.

Further, samples of chipboards were prepared by mixing thermally modified wood particles and an aqueous solution of polyvinyl alcohol in the ratios of components provided in Table 1.

Table 1. Composition of composite samples.

\begin{tabular}{|c|c|c|c|c|c|c|}
\hline \multirow{2}{*}{ Component } & \multicolumn{7}{|c|}{ Resulting humidity } \\
\cline { 2 - 7 } & $10 \%$ & $20 \%$ & $30 \%$ & $40 \%$ & $55 \%$ & $70 \%$ \\
\hline Completely dry sawdust, g & 150 & 150 & 150 & 150 & 150 & 150 \\
& & & & & & \\
\hline Completely dry PVAL, g & 100 & 100 & 100 & 100 & 100 & 100 \\
\hline Water, g & 15 & 30 & 45 & 60 & 82.5 & 105 \\
\hline
\end{tabular}

The prepared samples were tested for drying speed according to the previously developed vacuum technology [1]. The levels of variation of various drying factors are shown in Table 2. 
Table 2. Variable factors and their levels of variation.

\begin{tabular}{|c|c|c|c|c|c|c|}
\hline \multirow{2}{*}{ Factor } & \multicolumn{2}{|c|}{ Designation } & Interval & \multicolumn{3}{|c|}{ Level of variation } \\
\cline { 2 - 7 } & Natural & $\begin{array}{c}\text { Norma } \\
\text { lized }\end{array}$ & $\begin{array}{c}\text { of } \\
\text { variation }\end{array}$ & $\begin{array}{c}\text { Lower } \\
(-1)\end{array}$ & Main (0) & $\begin{array}{c}\text { Upper } \\
(+1)\end{array}$ \\
\hline $\begin{array}{c}\text { Density of wood-particle } \\
\text { composite, } \mathrm{kg} / \mathrm{m}^{3}\end{array}$ & $\rho$ & $\mathrm{X}_{1}$ & 100 & 600 & 700 & 800 \\
\hline Board thickness, $\mathrm{mm}$ & $\mathrm{S}$ & $\mathrm{X}_{2}$ & 15 & 16 & 32 & 48 \\
\hline Material temperature, ${ }^{\circ} \mathrm{C}$ & $\mathrm{T}$ & $\mathrm{X}_{4}$ & 10 & 90 & 100 & 110 \\
\hline $\begin{array}{c}\text { Residual pressure at the } \\
\text { vacuum stage, } \mathrm{kPa}\end{array}$ & $\mathrm{P}_{\mathrm{res}}$ & $\mathrm{X}_{5}$ & 15 & 20 & 35 & 50 \\
\hline \multicolumn{7}{|c|}{ Free moisture removal } \\
\hline $\begin{array}{c}\text { Average chipboard } \\
\text { moisture content, \% }\end{array}$ & $\mathrm{W}$ & $\mathrm{X}_{3}$ & 15 & 40 & 55 & 70 \\
\hline \multicolumn{7}{|c|}{ Bound moisture removal } \\
\hline $\begin{array}{c}\text { Average chipboard } \\
\text { moisture content, \% }\end{array}$ & $\mathrm{W}$ & $\mathrm{X}_{3}$ & 10 & 10 & 20 & 30 \\
\hline
\end{tabular}

Similarly to [1], to improve the accuracy of the mathematical description of the drying rate of wood composites, the technology was considered in two humidity intervals: $70-$ $40 \%$ and $30-10 \%$.

\section{Results}

Due to the fact that thermal modification results in a decrease in hygroscopicity and water absorption of wood, no significant moisture content of wood particles was observed during the formation of samples. This explains the higher rate of drying of composites with thermally modified filler compared to samples based on untreated wood particles [1]. Based on the experiments, the heat-treated wood filler-based wall board drying rate curves were plotted (Figure 2)

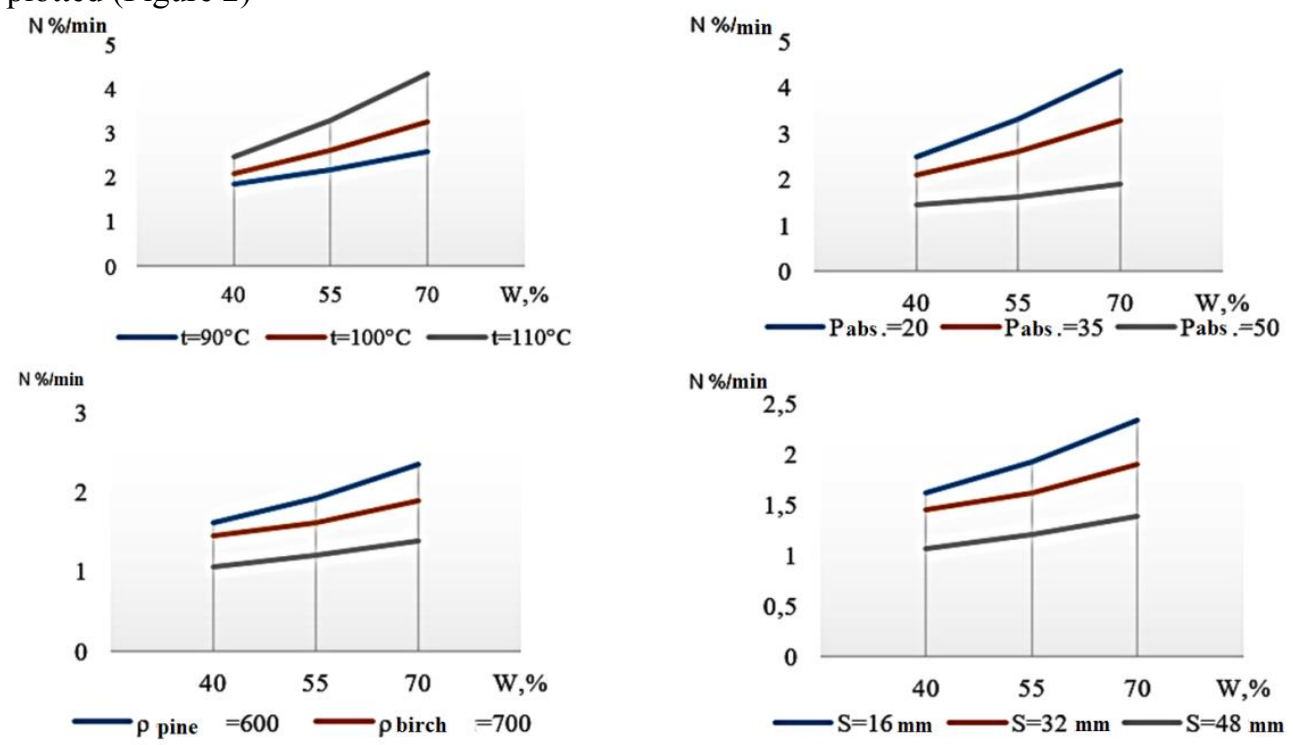

Fig. 2. Curves of the drying rate of the chipboard based on heat-treated wood filler and an aqueous solution of polyvinyl alcohol in the humidity range from 80 to $40 \%$ in different process modes and material parameters: $a$ - at different temperatures of the heating plate; $b$ - at different pressures in the chamber; $\mathrm{C}$ - at different density of the plate, $\mathrm{d}$ - at different thickness of the board. 

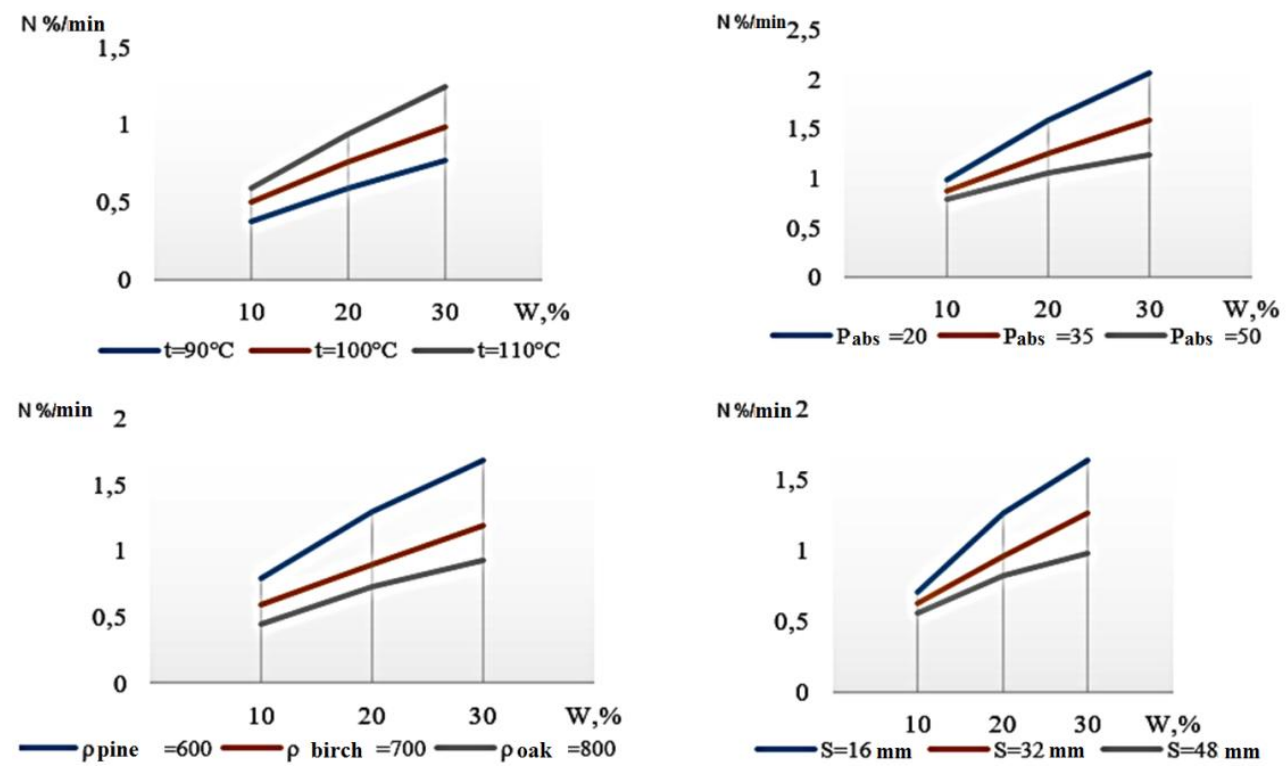

Fig. 3. Curves of the drying rate of chipboards based on heat-treated wood filler and an aqueous solution of polyvinyl alcohol in the humidity range from 30 till 10\%: a - at different temperatures of the heating plate; $\mathrm{b}$ - at different pressures in the chamber; $\mathrm{c}$ - at different density of the board, $\mathrm{d}$ - at different thickness of the board.

Based on the experiment planning and the experimental data presented in Figures 2 and 3 , regression equations were created for drying rate of samples of wall chipboard based on thermally modified wood filler and polyvinyl alcohol:

- for material humidity above the cell walls humidification limit:

$\mathrm{N}^{\prime}=4.014482+(-0.5192) \cdot((\rho-700) / 100)-0.53297 \cdot((\mathrm{S}-32) / 16)+0.873418 \cdot((\mathrm{W}-55) / 15)+$ $\left.+0.329745 \cdot((\mathrm{T}-100) / 10)-0.12711 \cdot\left(\left(\mathrm{P}_{\mathrm{res}}-35\right) / 15\right)+1.411863 \cdot((\rho-700) / 100) \cdot(\mathrm{S}-32) / 16\right)+$ $+1.12775 \cdot((\rho-700) / 100) \cdot((\mathrm{W}-55) / 15)+1.217938 \cdot((\rho-700) / 100) \cdot(\mathrm{T}-100) / 10)+1.185438 \cdot$ $((\rho-700) / 100) \cdot\left(\left(\mathrm{P}_{\text {res }}-35\right) / 15\right)+1.105 \cdot((\mathrm{S}-32) / 16) \cdot((\mathrm{W}-55) / 15)+1.253688 \cdot((\mathrm{S}-32) / 16) \cdot$ $((\mathrm{T}-100) / 10)+1.091188 \cdot((\mathrm{S}-32) / 16) \cdot\left(\left(\mathrm{P}_{\text {res }}-5\right) / 15\right)+1.282938 \cdot((\mathrm{W}-55) / 15) \cdot((\mathrm{T}-100) / 10)$ $\left.\left.+1.490125 \cdot((\mathrm{T}-100) / 10) \cdot\left(\mathrm{P}_{\mathrm{res}}-35\right) / 15\right)+1.152938 \cdot((\mathrm{W}-55) / 15) \cdot\left(\mathrm{P}_{\mathrm{res}}-35\right) / 15\right)-0.54241 \cdot((\rho-$ $700) / 100)^{2}+(-0.54241) \cdot((\mathrm{S}-32) / 16)^{2}-0.54241 \cdot((\mathrm{W}-55) / 15)^{2}-0.54241 \cdot((\mathrm{S}-32) / 16)^{2}$ $+0.354588 \cdot\left(\left(\mathrm{P}_{\text {res }}-35\right) / 15\right)^{2}$

- for material humidity below the cell walls humidification limit:

$\mathrm{N}=" 1.496325+0.513087 \cdot((\rho-700) / 100)+0.523058 \cdot((\mathrm{S}-32) / 16)+0.636638 \cdot((\mathrm{W}-20) / 10)$ $\left.+0.572407 \cdot((\mathrm{T}-100) / 10)+0.406829 \cdot\left(\left(\mathrm{P}_{\mathrm{res}}-35\right) / 15\right)+0.580125 \cdot((\rho-700) / 100) \cdot(\mathrm{S}-32) / 16\right)$ $+0.524438 \cdot((\rho-700) / 100) \cdot((\mathrm{W}-20) / 10)+0.5285 \cdot((\rho-700) / 100) \cdot(\mathrm{T}-100) / 10)+0.550063 \cdot$ $((\rho-700) / 100) \cdot\left(\left(\mathrm{P}_{\text {res }}-35\right) / 15\right)+0.492844 \cdot((\mathrm{S}-32) / 16) \cdot((\mathrm{W}-20) / 10)+0.519656 \cdot((\mathrm{S}-32) / 16)$ $\cdot((\mathrm{T}-100) / 10)+0.556594 \cdot((\mathrm{S}-32) / 16) \cdot\left(\left(\mathrm{P}_{\mathrm{res}}-5\right) / 15\right)+0.598844 \cdot((\mathrm{W}-20) / 10) \cdot((\mathrm{T}-$ $\left.\left.100) / 10)+0.483094 \cdot((\mathrm{T}-100) / 10) \cdot\left(\mathrm{P}_{\mathrm{ocT}}-35\right) / 15\right)+0.566781 \cdot((\mathrm{W}-20) / 10) \cdot\left(\mathrm{P}_{\mathrm{ocT}}-35\right) / 15\right)-$ $0.21538 \cdot((\rho-700) / 100)^{2}+(-0.21538) \cdot((\mathrm{S}-32) / 16)^{2}-0.21538 \cdot((\mathrm{W}-20) / 10)^{2}+(-0.21538) \cdot((\mathrm{S}$ $-32) / 16)^{2}+0.317619 \cdot\left(\left(\mathrm{P}_{\text {res }}-35\right) / 15\right)^{2}$ 


\section{Conclusion}

The research is aimed at creating eco-friendly wall materials. The authors have studied the technology of high-temperature treatment (thermal modification) of wood and its influence on the technological process of production of chipboard panels based on a polyvinyl alcohol binder. The paper presents the results of experimental studies of vacuumconductive drying of wall panels made of thermally modified filler. Drying curves for wall panels were plotted depending on various parameters: temperature conditions, different chipboard thickness, and the residual pressure in the vacuum chamber. In the course of this work, it was found that panels with a thermally modified filler dry much faster than those with an untreated filler.

Planning and conducting experiments on vacuum-conductive drying of chipboard samples from thermally modified wood particles and polyvinyl alcohol, enabled us to create a mathematical model of the drying rate during molding and pressing chipboard depending on the press heating temperature, chamber pressure, thickness and density of the molded products.

The work was supported by a grant from the President of the Russian Federation to support young Russian scientists who have a Ph.D. degree (MK-2246.2020.8).

\section{References}

1. J.S. Tumuluru, S. Sokhansanj, C.T. Wright, R.D. Boardman, R.J. Hess, Review on biomass torrefaction process and product properties and design of moving bed torrefaction system model development, American Society of Agricultural and Biological Engineers Annual International Meeting 2011, ASABE 2011, 7, 5886-5924 (2011)

2. H. Militz, S. Lande, Challenges in wood modification technology on the way to practical applications, Wood Material Science and Engineering, 4 (1-2), 23-29 (2009)

3. P. Koleda, M. Korčok, S. Barcík, S. Ilaš, Effect of Temperature of Heat Treatment on Energetic Intensity of Flat Milling of Picea Abies, Management Systems in Production Engineering, 26 (3), 151-156 (2018)

4. R.R. Safin, R.R. Khasanshin, I.F. Khakimzyanov, S.R.Mukhametzyanov, P.A. Kainov, Increasing the Energy Efficiency of the Process of Oscillating Vacuum-Conductive Drying of Wood by Means of a Heat Pump, Journal of Engineering Physics and Thermophysics, 90(2), 310-317 (2017)

5. R.R. Khasanshin, R.R. Safin, E.Y. Razumov, High Temperature Treatment of Birch Plywood in the Sparse Environment for the Creation of a Waterproof Construction Veneer, Procedia Engineering, 150, 1541-1546 (2016)

6. R.R. Safin, G.A. Talipova, N.R. Galyavetdinov, F.V. Nazipova, R.V. Salimgaraeva, The Study of the destructiveProperties of wood-filled Composites for the Production of biodegradable packaging Materials, International Multidisciplinary Scientific GeoConference, SGEM, 19, 541 (2020)

7. M.L. Fishman, D.R. Coffin, C.I. Onwulata, J.L. Willett, Two stage extrusion of plasticized pectin/poly(vinyl alcohol) blends, Carbohydrate Polymers, 65, 421429 (2006)

8. A. Corti, P. Cinelli, S.D. Antone, E.R. Kenawy, R. Solaro, Biodegradation of polyvinyl alcohol in soil environment: Influence of natural organic fillers and structural parameters, Macromol. Chem. and Phys, 203, 12 (2002) 
9. Jessica Thais de Lira Bazzetto, Geraldo Bortoletto Junior,Flavia Maria Silva Brito, The Influence of Processing and Particle Size on Binderless Particleboards Made from Arundodonax L. Rhizome, Polymers, 12 (2020)

10. R. Safin, Š. Barcík, A. Shaikhutdinova, P. Kaynov, E. Razumov, Development of the energy-saving technology of thermal modification of wood in saturated steam, Acta Facultatis Xylologiae, 57(2), 39-47 (2015)

11. E.Y. Razumov, R.R. Safin, S.Š. Barcík, M. Kvietková, ,R.R. Khasanshin, Studies on mechanical properties of composite materials based on thermo modified timber, Drvna Industrija, 64(1), 3-8 (2013) 